\title{
PRINCÍPIO DA LEGALIDADE E PODER REGULAMENTAR NO ESTADO CONTEMPORÂNEO*
}

\author{
AleXandre Santos de Aragão*
}

1. Princípio da separação dos poderes. II. Princípio da legalidade. III. $O$ exercício de funções normativas pela administração pública. III.1. Delegificação. IV. conclusão.

"On ne voit rien de juste ou d'injuste qui ne change de qualité en changeant de climat; trois degrés d'élévation du pôle renversent toute la jurisprudence; une méridien décide de la verité... le droit a ses époques... plaisante justice qu'une rivière borne, verité en deça des Pyrénées, erreur au dela!'

Pascal. $^{1}$

Um dos pontos do Direito Público que mais tem desafiado os juristas e operadores do Direito no mundo contemporâneo é a multiplicação das normas genéricas e abstratas editadas por órgãos e entidades não integrantes do Poder Legislativo, que, se por um lado, nos leva à reavaliação dos contornos das funções que este hoje possui, por outro, faz com que procedamos à revisão conceitual do próprio Poder Executivo, historicamente concebido como um gestor dos assuntos públicos, subalterno e executor das decisões do Parlamento. ${ }^{2}$

* Texto elaborado a partir da transcrição de palestra proferida sob o mesmo título na Pontifícia Universidade Católica do Rio de Janeiro - PUC/RJ em 12 de abril de 2000.

* Procurador do Estado do Rio de Janeiro, Professor contratado de Direito Administrativo da Universidade do Estado do Rio de Janeiro - U.E.R.J. e da Universidade Estácio de Sá, membro das Comissões de Direito Administrativo e de Direito Constitucional do Instituto dos Advogados Brasileiros - IAB, Mestrando em Direito Público pela U.E.R.J.

1 In "Pensées", Ed. Jacques Chevalier, 1925, T. I, p. 126.

2 Javier García Fernández, in "El Gobierno en Acción", Cuademos y Debates, $\mathrm{n}^{\circ}$ 57, Boletín Oficial del Estado, Centro de Estudios Constitucionales, Madrid, 1995, pp. 50/1. 
Já em 1965, Vicente Ráo ${ }^{3}$ reconhecia que não havia "como se desconhecer que a maior extensão dos deveres do Estado moderno, para além da ordem estritamente jurídica, exige se lhe confiram novos poderes, para o exercício dos quais há de se apresentar instrumentalmente aparelhado, a fim de poder exercer as suas funções a tempo e com eficiência. (...) Tem-se sustentado ser necessário que o Governo possua e mantenha em atividade um sistema adequado de meios e instrumentos de disciplina equacionado com a especialização e a complexidade crescente dos problemas sociais e particularmente dos problemas econômicos contemporâneos. E mais se tem dito e vem dizendo que esses meios e instrumentos devem possuir flexibilidade bastante para prevenir ou remediar tempestivamente as crises ocorrentes, o que jamais se conseguiria obter se a ação do Estado devesse depender só e sempre das insuficiências e das delongas dos processos legislativos tradicionais, ou seja, das assembléias constituídas por centenas de membros em sua maior parte desprovida de conhecimentos técnicos especializados e atentos, as mais das vezes, aos interesses das forças que os elegeram do que às necessidades reais da nação."

Ao adentrar no tema, não menosprezaremos a importância dos princípios da separação dos poderes e da legalidade, mas tentaremos libertá-los do véu mítico que às vezes os encobre. ${ }^{4}$

\section{I - Princípio da separação dos poderes}

Marcadamente após a $2^{\mathrm{a}}$ Guerra Mundial, quando as atividades estatais adquiriram, frente a uma realidade tecnicizada e cambiante, inédita complexidade, a normatização social passou a ser crescentemente exercida por órgãos não integrantes do Poder Legislativo, mormente por órgãos e entidades da Administração Pública.

O panorama é amplíssimo, abrangendo desde órgãos centralizados da Administração Direta e antigas instituições, como as universidades, até as recentes agências reguladoras.

Os poderes regulamentares conferidos à Administração Pública não apenas são inúmeros, abrangendo a maior parte dos setores da vida social, como, pelos termos bastante genéricos em que são conferidos, são exercidos com elevado grau de liberdade.

3 In "As Delegações Legislativas no Parlamentarismo e no Presidencialismo", Ed. Max Limonad, São Paulo, 1966, pp. 16 a 18.

4 O tema implica na abordagem de inúmeros aspectos de relevância para a Teoria Geral do Estado. Não será o caso, todavia, de esgotá-los. Os temas periféricos serão tratados de maneira instrumental à compreensão do objeto principal do estudo. Buscaremos, no entanto, sugerir alguma bibliografia que possa auxiliar no aprofundamento das abordagens feitas. 
Mais uma vez confirma-se a assertiva de que toda importante questão de direito público chega, mais cedo ou mais tarde, ao, tão antigo quanto polêmico, princípio da separação dos poderes. ${ }^{5}$

Por ora, devemos observar que a Teoria de Montesquieu, historicamente contextualizada nos séculos XVII e XVIII, além de ter sido objeto de interpretações radicais e absolutas, não contempladas pelo próprio autor, nunca foi aplicada em sua inteireza. $^{6}$

Em primeiro lugar, não existe uma separação de poderes, mas muitas, variáveis segundo cada Direito positivo e cada momento histórico. ${ }^{7}$

Se retirarmos o caráter dogmático e sacramental impingido ao princípio, ele poderá, mantendo a substância, ser colocado em seus devidos termos, ou seja, como divisão das atribuições do Estado entre órgãos distintos, ensejando uma salutar divisão de trabalho e um empecilho à historicamente perigosa concentração de poderes.

Ele não é capaz, contudo, de levar à conclusão de que cada um destes distintos órgãos-Poderes só possa exercer uma das três funções tradicionalmente consideradas - legislativa, executiva e judicial. E mais, também não é capaz de fazer com que todas as funções do Estado devam necessariamente se subsumir a apenas uma destas três principais espécies classificatórias de funções estatais.

As considerações de Karl Loewenstein ${ }^{8}$ a respeito da forma com que o princípio da separação dos poderes deve ser hodiernamente enfocado são muito esclarecedoras:

“O que na realidade significa a assim chamada 'separação de poderes', não é, nada mais nada menos, que o reconhecimento de que, por um lado, o Estado tem que cumprir determinadas funções - o problema técnico da divisão do trabalho - e que, por outro, os destinatários do poder sejam beneficiados se estas funções forem realizadas por diferentes órgãos: a liberdade é o telos ideológico da teoria da separação de poderes. (...) O que, comumente, ainda que erroneamente, se costuma denominar como a separação dos poderes estatais, é na verdade a distribuição de determinadas funções estatais a diferentes órgãos do Estado. $O$ conceito de 'poderes', apesar de estar profundamente enraizado, deve ser entendido neste contexto

5 "Malgré l'apparente précision des textes, il ne faut croire que la fameuse théorie de Montesquieu sur la Séparation des pouvoirs soit parfaitement claire et facilement intelligible. La meilleure preuve qu'il n'en rien, c'est qu'elle a donné e donne encore matière à des discussions passionés et à des interprétations innombrables. (...) Bien rares sont les études pleinement objectives et exemptes de toute préocupation tendancieuse" (Marcel de la Bigne de Villeneuve, in "La Fin du Principe de Séparation des Pouvoirs", Sirey, 1934, p. 9).

6 Cf. Reinhold Zippelius, in "Teoria Geral do Estado", Fundaçāo Calouste Gulbenkian, 3" ed., 1997, trad. Karin Praefke-Aires Coutinho, Coordenação de J. J. Gomes Canotilho, p. 416.

7 Ibid.

8 In "Teoría de la Constitución", Ariel, 1986, trad. Alfredo Gallego Anabitarte, pp. 55/6. 
de uma maneira meramente figurativa. Na exposição a seguir se preferirá a expressão 'separação de funções' a de 'separação de poderes'."

Prossegue o constitucionalista, observando que "é necessário ter bem claro que o princípio da necessária separação das funções estatais segundo seus diversos elementos substanciais e sua distribuição entre diferentes detentores, não é nem essencial para o exercício do poder político, nem se apresenta como uma verdade evidente e válida para todo tempo. O descobrimento ou invenção da teoria da separação de funções foi determinada pelo tempo e pelas circunstâncias como um protesto ideológico do liberalismo político contra o absolutismo monolítico da monarquia nos séculos XVII e XVIII."

Similar tratamento à separação de poderes é dado por Reinhold Zippelius ${ }^{9}$ ao afirmar que a 'clássica' divisão dos poderes assenta na distinção entre os âmbitos funcionais mais importantes do Estado. Os objetivos supremos da actividade do Estado devem ser permanentemente elaborados, revistos, harmonizados entre eles, e modificados na medida do necessário.(...) Desta maneira se projectam antecipadamente futuros modelos de ordenação e planos de acção relativos à política interna e externa. Tudo isto, que vai para além da mera execução das leis, é tarefa do governo que, como suprema actividade directiva do Estado, não se encaixa, portanto, sem problemas no esquema 'legislação, jurisdição e poder executivo'."

Com efeito, "na atualidade o sistema de divisão e limitação dos poderes se desenvolveu a partir de vários pontos de vista, não apenas na conhecida e tradicional trindade da divisão horizontal de acordo com as funções mais importantes: legislativo, executivo e judicial. Mas também entram em jogo a configuração de unidades de decisão e órgãos coletivos, a autonomização de instituições específicas não submetidas a instruções, e a constituição ainda de instâncias de controle tampouco submetidas a instruções, a margem da divisão tripartite "clássica". ${ }^{10}$

A separação de poderes deve ser vista atualmente sob o prisma do pluralismo da nossa sociedade, que "tem o significado de colocar perante várias instâncias da máquina estadual as reclamações ou o apoio de vozes diferentes. E assim resulta numa potenciação da divisão de poderes organizatória interna do Estado, que ganha outra vez o valor duma divisão política. Só que em vez da fórmula do século XIX de uma separação taxante entre pretendentes ao poder, cada um com o seu veículo de expressão numa "função" do Estado, vamos encontrar um sistema bem mais complexo e subtil (...). O pluralismo social vem assim a integrar-se num quadro alargado de separação de poderes, e representa uma função positiva na organização dum estado moderno." $" 1$

9 In ob. cit., p. 412.

10 Klaus Stern, in "Derecho del Estado de la Republica Federal Alemana", Centro de Estudios Constitucionales, 1987, trad. Javier Pérez Royo e Pedro Cruz Villalón, p. 236.

11 Rogério Guilherme Ehrhardt Soares, in "Direito Público e Sociedade Técnica", Atlântica Editora, Coimbra, 1969, p. 160. 
$\mathrm{Na}$ doutrina brasileira, Bilac Pinto ${ }^{12}$, em obra pioneira, asseverou que "o fato da outorga, pelo Estado moderno, de funções normativas e jurisdicionais a outros órgãos além dos que as monopolizaram, até o fim do século passado (Poder Legislativo e Poder Judiciário), constitui fenômeno universal, cujas proporções se avolumam cada vez mais."

Com escusas pelas citações, acreditamos ter demonstrado que, se relativizada a idéia "clássica" e absoluta de separação dos poderes, o amplo poder regulamentar dos órgãos e entidades da Administração Pública em nada contraria a divisão de funções estabelecida pelas constituições contemporâneas e os valores do Estado de Direito, que, afinal, constituem o principal parâmetro da admissibilidade ou não do exercicio de distintas funções estatais pelo mesmo órgão-Poder. ${ }^{13}$

Espancando quaisquer perplexidades, o clássico JEAN DABIN,,${ }^{14}$ com percuciência, asseverou: "Se idealmente fundada a distribuição de funções entre instituições ou órgãos distintos e independentes, ela não possui, todavia, senão um valor de meio, não de um dogma, o que vale dizer que o princípio comporta uma série de exceções. As exceções serão justificadas, em primeiro lugar, toda vez que razões de interesse geral as imponham. A hipótese é bastante frequiente, mas sempre especial. Normalmente, por outro lado, do ponto de vista teórico, a solução derrogatória é aplicada ou pela história das instituições ou por considerações de oportunidade."

\section{II - Princípio da legalidade}

A determinação do âmbito do poder normativo dos órgãos não integrantes do Poder Legislativo pressupõe a definição do que se entende por Estado de Direito, separação de poderes, princípio da legalidade e discricionariedade.

À complexidade destas matérias agrega-se $o$ fato de que parte da doutrina brasileira mantém a respeito delas uma concepção ainda apegada às suas origens mais remotas, totalmente diversas da realidade do Estado contemporâneo.

O princípio da legalidade tem a sua origem na noção liberal oitocentista de separação de poderes. A classe burguesa, prevenindo-se das medidas que até então lhe eram impingidas pela realeza absolutista, estabeleceu, pelo menos teoricamente, um mecanismo pelo qual toda medida jurídica seria mera decorrência, simples subsunção ou execução, de normas jurídicas adredemente estabelecidas por seus representantes de maneira genérica, abstrata e exaustiva. Ao administrador e ao juiz incumbiria, portanto, apenas a execução da lei, tendo funções meramente cognitivas, nunca volitivas.

12 In "Regulamentação Efetiva dos serviços de Utilidade Püblica", Ed. Revista Forense, 1941, p. 107.

13 Em outras palavras, não serão as acumulações de poderes sempre constitucionais, mas, certamente o serão, se privilegiarem os valores do Estado de Direito.

14 In "Doctrine Générale del 'État", Bruylant e Sirey, Bruxelas e Paris, 1939, pp. 284/5, grifamos. 
À lei do parlamento foi, então, impingido um valor sacramental, fundado na noção de "vontade nacional" ou "popular", e nas idéias racionalistas e humanistas predominantes na época. ${ }^{15}$ Qualquer ato administrativo ou judicial que não representasse única e exclusivamente a concreção da vontade previamente estabelecida pelo legislador seria um atentado à vontade do novo soberano, o "povo-rei", sendo, assim, ilegítima.

A "vontade popular", até hoje invocada para fundamentar a defesa da subordinação absoluta do administrador e do juiz à lei deve, no entanto, ser relativizada.

O homem sempre precisou de normas estáveis e previsíveis pelas quais pudesse pautar o seu comportamento, tendo criado ao longo da história os mais diversos fundamentos para que se conformasse às limitações impostas à sua liberdade.

Até à consolidação política da cristianização na Europa, os grupos humanos possuíam uma estrutura jurídica simples, geralmente fundada na autoridade do chefe do clã. $O$ surgimento da lei, ainda não parlamentar, mas já com suas características de certeza, abstração e generalidade, surgiu apenas com a sedentarização e aglomeração dos grupos humanos nas cidades que começavam a surgir. A convivência de diversos grupos sociais no mesmo espaço territorial urbano impossibilitou a subsistência de uma ordem jurídica semi-consensual, passando a ser exigida uma disciplina jurídica uniforme que fosse considerada legítima por todos os grupos.

O que havia de comum entre estes diversos grupamentos humanos reunidos nas cidades era a fé católica. Desta forma, o ordenamento jurídico global impôs-se fundado na vontade de Deus, manifestada através dos clérigos ou do Rei. Mais tarde, em virtude da Reforma Protestante, que quebrou o consenso religioso até então existente, a vontade do Rei passou a legitimar-se por si própria.

Com a Revolução Francesa, apenas houve uma mudança no ícone legitimador da lei, que passou a fundamentar-se na, não menos mítica, "vontade popular".

Observa-se que as eleições eram censitárias e que, tal "vontade", derivava não "da nação" ou "do povo", mas da maioria dos seus representantes, eleitos pela parcela da população que pagava uma certa quantia mínima em tributos.

Também o voto dos representantes não era (e não é) necessariamente motivado apenas pelo interesse público, deixando-se influenciar muitas vezes por grupos sociais específicos, na maioria das vezes dotados de grande poder econômico. ${ }^{16}$

15 "O idealismo do iluminismo se traduziu, já no século XVIII, numa certa idéia do homem, por aspiração à felicidade e ao progresso. O pensamento liberal burguês da época revolucionária, movido por uma inspiração filosoficamente heterogênea, celebrou ao mesmo tempo os "prodígios da lei" promulgada pelo Poder e as virtudes dos "Direitos-liberdades" oponíveis ao Poder" (Simone Goyard-Fabre, in " Os Princípios do Direito Político Moderno", trad. Irene A. Paternot, Ed. Martins Fontes, 1999, p. 309).

16 São clássicas as lições de Carl Schmitt a respeito da manipulação da lei para a satisfação de interesses políticos ou econômicos não muito nobres e a sua "apropriação" por setores parciais da sociedade (in "Du Politique - Legalité et Legitimité et Autres Essais", Ed. Pardès, Puiseaux, 1990, tradução coletiva não especificada, pp. 39 a 80 e 215 a 224). 
A lei parlamentar é, no fundo, dentre outros teoricamente possíveis, um dos procedimentos técnicos de formulação de normas jurídicas. ${ }^{17} \mathrm{~A}$ "vontade popular", tal como a "vontade de Deus" ou "do Rei", é apenas um fundamento metafísico que é, ao mesmo tempo, imposto e criado pelos destinatários das normas.

A verdadeira essência da lei não reside nos variados fundamentos oriundos de especulações filosóficas ou teológicas que encontraram eco na psique humana ao longo da história. Decorre, ao revés, da necessidade prática de segurança jurídica, de sabermos, com algum grau de pré-determinação, o que podemos e o que não podemos fazer e, em caso de inobservância, que consequiências poderemos sofrer.

Merece, pela sua profundidade e erudição, ser trazida à baila a lição de Henri de Page ${ }^{18}$ na qual observa que " na prática diária, com serena cegueira, lidamos com uma noção vazia de sentido, e que, no entanto, fez uma revolução: A Soberania popular. (...) A solução do problema, depurada dos elementos heterogêneos que a poluem, reside na compreensão de uma situação de fato, de um estágio sociológico determinado. (...) Desvestimo-nos do velho homem. Examinando as coisas mais friamente, livrando a noção de lei desta ganga de moral e de preconceitos de toda espécie que, por si próprios, criaram o seu hieratismo, tratando-a como um fato social qualquer, como uma coisa e não como a obra de uma vontade divina ou humana, alcançaremos realidades e potencialidades mais fecundas e proveitosas. (...)

A lei já foi a expressão da vontade de Deus, depois a vontade do príncipe. Atualmente, acreditamos que seja a expressão da soberania do povo. Estas são as qualificações morais, sentimentais, que destorcem a sua noção essencial, a ser buscada apenas no seu fundamento obrigatório. Religiosa ou laica, hipostasiada na vontade de Deus ou dos homens, a lei sempre foi o fenômeno social que acabamos de descrever, cumprindo uma finalidade histórica imutável. As formas "morais" da vontade divina ou humana não são nada além de adereços superficiais, aparências imaginadas por sucessivas ilusões metafísicas. O importante é encontrar a justificação de todos estes fenômenos históricos direcionados à "legislação", e nos objetivos perseguidos por todos os legisladores. Ditado por Jeovah, Moisés gravou em doze tábuas de pedra, símbolos de imobilização e de estabilidade durável, os princípios de uma religião até então fluidos e incertos, cristalizando a sua aplicação em dez preceitos que os englobava totalmente. Em Roma, os antigos magistrados - decênviros - fixaram, sob doze tábuas, as regras pelas quais patrícios e plebeus deveriam a partir de então viver e agir. (...) $\mathrm{E}$ as codificações modernas, produzidas normalmente após uma unificação política ou social, tiveram como principal função resumir o direito aplicável, e enquadrar a sua totalidade em uma carta solene e definitiva. Pode-se concluir claramente que a estrutura lei constitui uma tentativa de localização, de fixação, de imobilização das forças esparsas e fugidias, independentemente de ter como fundamento Deus, a consciência ou os fatos, captadas pelos textos e

17 Francos Geny, in "Science et Thechnique en Droit Privẻ Positif", T. III, apud Henri De Page, in "De l'Interprétation des Lois - Contribution à la recherche d'une méthode positive et théories en présence", Librarie Payot \& Cie., Bruxelas, 1925, p. 25.

18 In, ob. cit., T. I, pp. 24/8 (grifamos). 
destinadas, por consolidação, a tornar-se um programa, uma disciplina da atividade social". ${ }^{19}$

Colocado o fenômeno "lei do parlamento" de maneira realista, sem jamais desmerecer os seus inegáveis méritos e a função de estabilização social que desempenha, podemos passar a tratar a matéria com a objetividade necessária.

Inicialmente, devemos destacar que o objetivo almejado pelo liberalismo do século XVIII, do absoluto império da lei, nunca foi atingido. Logo foi verificada a incompletude das leis, o que exigiu, tanto no Direito privado, como no público, uma progressiva construção jurisprudencial, criadora até mesmo de novos institutos jurídicos (teoria da imprevisão, vedação do enriquecimento sem causa, responsabilidade civil do Estado, abuso de direito, desvio de finalidade etc.).

No que diz respeito exclusivamente ao desenvolvimento das atividades administrativas, também não demorou para ser constatada a impossibilidade da lei estabelecer prévia e exaustivamente todos os atos que o administrador deveria, de forma autômata, praticar para proteger o interesse público.

Impôs-se ao legislador que, na impraticabilidade de prever todas as situações que demandariam a atuação do Poder Público, concedesse à Administração certa liberdade para determinar o conteúdo dos seus preceitos. As leis passaram então a ser mais gerais e menos determinadas. Essa técnica legislativa recebeu o nome de discricionariedade. ${ }^{20}$

Tratando do momento histórico da afirmação da discricionariedade, Maurice Hauriou ${ }^{21}$ afirmou: "A lei foi colocada sob um pedestal e uma teoria jurídica foi construída para reconduzir todo o direito à regra de direito e para subordinar a esta todo o poder, recusando ao poder discricionário qualquer relevância jurídica. Para responder a estes exageros, será suficiente recordar que mesmo na França pós-revolucionária, a supremacia da lei escrita lentamente declinou e que, por um movimento inverso, restaurou-se lentamente o poder dos juízos discricionários, a ponto que fosse restabelecido, entre os dois domínios, um novo equilíbrio."

Devemos ir um pouco mais além: a própria vinculação administrativa, tida como um conceito oposto ao de discricionariedade, não deve ser entendida em termos absolutos. Como explicitado por Bartolomé A. Fiorini, para uma correta distinção entre atos administrativos vinculados e discricionários "é necessário excluir do pensamento jurídico o sentido absoluto pretendido pela clássica definição, ao considerar a administração como a execução direta da lei. Esta, que teve sua origem nos estudos de Rousseau no seu Contrato Social, foi propagada logo, sem maior

19 Maurice Hauriou, discorreu sobre o mesmo fenômeno em termos semelhantes, afirmando que, o que verdadeiramente importa para a lei, é que ela seja escrita, pública, geral, abstrata e racional (in "Aux Sources du Droit", Librarie Bloud \& Gay, Paris, 1933, pp. 182 e segs.).

20 Malgrado não ser inteiramente coincidente a que adotamos, é notável a conceituação de discricionariedade de Karl Engisch, constante do seu "Introdução ao Pensamento Juridico", Fundação Calouste Gulbenkian, 7 ed., 1997, trad. J. Baptista Machado, pp. 115 a 274. Quanto à preponderância das razões de ordem prática no surgimento da discricionariedade, ver André de Laubadère, in "Traité de Droit Administratif", T. 1, LGDJ, Paris, 15" ed., 1999, p. 693.

21 In ob. cit., pp. 184 e 185. 
análise, o que desviou muitos juristas. (...) Ao fazer tal consideração, excluem o trecho fecundo onde a administração pode manifestar distintos atos sem sair do cerco fechado da norma denominada lei. Não têm em conta que os atos, as normas administrativas, como a própria lei, só vinculam momentos jurídicos dos interesses coletivos em sua relação com a vida real." 22

Após a discricionariedade, o princípio da legalidade teve a sua concepção originária e, como visto, apenas ideal, ainda mais atenuada pela concessão de poderes normativos à Administração Pública a fim de que, ela própria - não o Poder Legislativo - estabelecesse normas gerais e abstratas, ou seja, criasse Direito positivo.

Se este fenômeno já havia se imposto no início do Estado liberal, essencialmente absenteísta, teve e tem a sua importância e âmbito multiplicados com o advento do Estado social, ${ }^{23}$ gestor de inúmeras atividades econômicas ou, mais recentemente, delas preponderantemente regulador. ${ }^{24}$

Portanto, logo após a vitória da concepção originária da separação absoluta dos poderes, iniciou-se com impressionante rapidez o que Eros Roberto Grau ${ }^{25}$ chamou de processo de "transformação (na verdade, involução)" do princípio da legalidade, que "originariamente implicava em que todo elemento de um ato da Administração deveria estar expressamente previsto como elemento de alguma hipótese normativa, devendo a norma fixar poderes, direitos, deveres, etc., modos e seqüência dos procedimentos, atos e efeitos de cada um dos seus componentes e requisitos de cada ato - do que resultava a concepção do Poder Executivo como administração e da administração como execução."

A denominação do "Poder Executivo", denotadora de uma concepção que o considera como mero executor das normas do Poder Legislativo, ${ }^{26}$ passou então a ser duramente criticada, dando-se preferência à expressão "Governo". Esta expres-

22 In "La Discricionariedad en la Administración Pública", Editorial Alfa, Buenos Aires, 1948, pp. 46/7. No mesmo matiz, Maurice Hauriou (in ob. cit., pp. 183/4) afirmou que "a própria lei escrita, para ser aplicada, necessita da atuação das autoridades que administram o direito."

23 Cf. Vezio Crisafulli, in "La Costituzione e le sue Disposizione di Principio", Dott. A. Giuffrè Editore, 1952, José Afonso da Silva, in "Aplicabilidade das Normas Constitucionais", Ed. Malheiros, $1998,3^{2} \mathrm{ed}$.

24 Cf. o nosso "Cofiguração do Estado Social Brasileiro na Constituição de 1988 - Reflexos na despublicização da atuação estatal", constante da obra coletiva "Temas de Direito Constitucional - Estudos em homenagem ao advogado André Franco Montoro", organizada por Guilherme José Purvin de Figueiredo e José Nuzzi Neto, Ed. Esplanada - ADCOAS/IBAP, Rio de Janeiro, 2000, pp. 21/58.

25 In "Algumas Notas para a Reconstrução do Princípio da Legalidade", Revista de Direito da Faculdade de Direito da USP, 78.

26 Cf. M. S. Giannini, in "Diritto Amministrativo", $1^{\circ}$ Volume, $3^{*}$ ed., Giuffrè Editore, Milão, 1993. À página 88, o autor afirma: "Questa concezione rigida del principio di legalità corrispondeva alla concezione del potere amministrativo come potere esecutivo, e quindi dell'amministrazione come esecuzione. Siccome in tal modo le amministrazioni pubbliche non avrebbero potuto funzionare, si trovarono due valvole, nella discrezionalità amministrativa, $e$ in taluni atti amministrativi da adottare solo in circostanze straordinarie, che erano le "ordinanze di necessità." 
são é, sem dúvida, tecnicamente mais correta por não escamotear a função fortemente política que possui, isto é, de que tal como os demais Poderes, também estabelece diretrizes e normas do Estado. Podemos até continuar a usar, por costume e tradição, a expressão "Poder Executivo", mas desde que tenhamos em mente a sua inexatidão terminológica.

O fato do Poder Legislativo não monopolizar toda a função normativa estatal, não implica, todavia, em desatenção ao Estado de Direito. Este não se confunde com o Estado legal ou Estado DO Direito. ${ }^{27}$

A pedra de cal no ideal legalista do iluminismo, segundo o qual as leis (do parlamento) seriam necessariamente justas e racionais, foi a série de iniqüidades por elas veiculadas ao longo da história (nazismo, fascismo etc.). Deu-se o que Louis Favoreu ${ }^{28}$ qualificou como a "dessacralização da lei": tendo-se percebido que poderia perfeitamente "causar danos às liberdades e direitos fundamentais dos indivíduos; é, portanto, necessário proteger-se também contra ela e não mais exclusivamente contra os atos do poder executivo; a lei não está mais no centro do sistema normativo."

Ademais, é, $d$. v., ingênua a posição segundo a qual o Poder Legislativo deve concentrar todo o poder normativo do Estado. O caráter lento e pouco técnico do processo legislativo inviabilizaria o desempenho das funções estatais na realidade contemporânea, cada vez mais complexa e dinâmica. Limitar as formas de atuação e organização estatal àquelas do século XVIII, ao invés de, como afirmado pelos autores mais tradicionais, proteger os direitos dos indivíduos e da sociedade, retiralhes a possibilidade de regulamentação e atuação efetiva dos seus interesses.

O que devemos é buscar a realização dos valores de justiça e eqüidade do Estado de Direito por parte de qualquer poder estatal. ${ }^{29}$ É mais importante satisfazê-los do que garantir a competência deste ou daquele Órgão Estatal/Poder. ${ }^{30}$

O mero Estado legal ou DO Direito consiste apenas no estabelecimento de uma regra de competência atributiva de sobrepujança do Poder Legislativo sobre os demais Poderes. O Estado DE Direito, ao revés, consubstancia-se numa ordem

27 Cf. Redor Marie-Joëlle na obra, eloquiente pelo seu próprio título, “De l'État légal à l'État de Droit", Ed. Economica, 1992.

28 In "A Evolução e a Mutação do Direito Constitucional Francês", constante da obra coletiva "Direito Constitucional - Estudos em Homenagem a Manoel Gonçalves Ferreira Filho", Ed. Dialética, 1999, p. 215.

29 "Les principes sont l'arme preferée des juristes. C'est grâce à eux que ces Prudents exercent leur magistère, tantôt en faveur de la jurisprudence, tantôt en faveur de la loi. A l'époque actuelle, ils sont, par la force des choses, poussés vers la jurisprudence plutôt que vers la loi" (Maurice Hauriou, in ob. cit., pp. 188/9).

30 Giorgio Del Vecchio, criticando os céticos e realistas empíricos, afirma que eles "identificam justiça com legalidade, justiça com comando. Fácil é mostrar que semelhante interpretação é própria das fases primitivas da evolução da sociedade ou do homem. Só a sociedade primitiva, ou a criança, são incapazes de distinguir entre o estatuído como justo e a justiça" (in "Lições de Filosofia do Direito", Coimbra, 1979, trad. Antônio José Brandão, p. 546). 
axiológica global. ${ }^{31}$ "Se o Estado DO Direito se caracteriza essencialmente por suas formas e suas estruturas jurídicas, é, no Estado DE Direito, a participação ideológica que prevalece sobre a arquitetônica jurídica e liga a esperança da liberdade à sua realização". ${ }^{32}$

Prevenindo-nos contra quaisquer perplexidades, Carlos Ari Sundfeld ${ }^{33}$ explica “porque a adoção de um amplo sistema de regulamentos autônomos ou o controle da produção legislativa pelo Executivo não eliminou o Estado de Direito: ainda que a norma a aplicar (lei, regulamento, diretiva comunitária, não importa) não os favoreça ou induza, sua aplicação há de seguir um "catálogo de mandamentos" que excluirá o arbítrio. (...) Em termos exclusivamente lógicos, o Estado de Direito pode prescindir da subordinação do ato administrativo à lei e do Executivo ao Legislativo. Basta preservar em vigor o dogma de que o ato da Administração não pode ser fruto do capricho (mesmo que não haja uma lei a sujeitá-lo.)".

\section{III - O exercício de funções normativas pela administração pública}

Dentro da perspectiva dos Tópicos anteriores, desenvolveremos a apreciação do poder normativo da Administração Pública, cuja compreensão é sobremaneira dificultada pelo conservadorismo de alguns, que têm verdadeira ojeriza à simples menção ao termo "regulamento autônomo". Podem até dar o nome de "executivo" a atos normativos que, indubitavelmente, sejam daquela espécie, mas, falar "autônomo", jamais. $^{34}$

O trato da matéria é estorvado também pelos que, apesar de terem uma visão mais atualizada e realista da matéria ${ }^{35}$ adotam nomenclatura diversa e confusa:

31 Redor Marie-Joëlle, in ob. cit., p. 389.

32 Simone Goyard-Fabre, in ob. cit., p. 322.

33 In "A Administração Pública na Era do Direito Global", constante da obra coletiva "Direito Global", Max Limonad, 1999, p. 167.

34 Esta era, como observa Javier García Fernández, a postura do Conselho de Estado francês: "A execução da lei significava, para o Conselho de Estado, assegurar o funcionamento dos serviços públicos e a manutenção da ordem pública, o que habilitava o Executivo a ditar regulamentos 'praeter legem'. Nesta doutrina estava implicita a função de governo, mas, todavia, o Conselho de Estado não saia do fetichismo da lei soberana, o que tornou tanto mais necessária uma doutrina que rompesse explicitamente com esta concepção" (in ob. cit., p. 64, grifamos).

35 Podemos citar neste campo, por exemplo, Eros Roberto Grau (in " $O$ Direito Posto e o Direito Pressuposto", Ed. Malheiros, $2^{\circ}$ ed., 1998, Capítulo 10), que entende que, além dos regulamentos de mera execução, dos excepcionais, existentes apenas em caso de estado de necessidade pública, e dos de simples organização interna, podem ser emitidos regulamentos autorizados (os casos em que a lei simplesmente dispōe que "O Poder executivo regulamentará tal matéria" — chamados pela doutrina tradicional, que não os admite, de delegados - Eros entende que não há delegação porque a competência exercida é do próprio Poder Executivo) e autônomos, quando a lei não trata em absoluto da matéria, mas o ordenamento jurídico como um todo, explícita ou implicitamente, dá esteio à atuação regulamentar do Poder Executivo. $O$ autor considera que, o que a doutrina tradicional chama de reserva relativa de lei, é, na verdade, "reserva de norma", decorrente sobretudo das elevadas e complexas funções da Administração Pública no Estado Social. 
regulamentos meramente executivos, executivos, interpretativos, autônomos, independentes, delegados, organizativos, livres, integrativos, de necessidade etc. Denominam as mesmas espécies regulamentares de maneira diferente, subdividem-nas, equiparam-nas, e assim em diante. ${ }^{36}$

Para sair desse emaranhado estéril, preferimos priorizar as distintas situações normativas das quais podem advir os regulamentos, não dando maior relevo às suas diversas denominações específicas, até porque, como poderemos concluir mais adiante, em última análise, a diferença entre elas concerne apenas ao grau, à amplitude, com que a discricionariedade ou o poder normativo é conferido. ${ }^{37}$ $\operatorname{dos}:^{38}$

Vejamos, pois, diante de que situações normativas os regulamentos são edita-

a) Leis de densidade normativa exaustiva, normalmente impostas por reserva absoluta de lei: A reserva absoluta de lei formal, vigente em nosso ordenamento para a instituição de tributos, de crimes e das respectivas penas (arts. 150, I e $5^{\circ}$, XXXIX, CF), segundo a doutrina tradicional, com a qual, neste aspecto, em parte concordamos, obriga o legislador a dispor sobre a matéria de forma completa, sendo-lhe vedado deixar qualquer espaço para juízos discricionários, sejam eles administrativos ou judiciais.

A assertiva é, até certo ponto, correta, mas sabemos que o caráter exaustivo da

36 Sobre a descrita confusão doutrinária, ver Lorenza Calassare, in "Regolamenti dell'Esecutivo e Principio di Legalità", CEDAM, 1966, p. 175 e segs. Focando o Direito Brasileiro, com ampla e atualizada narrativa das diversas correntes existentes, podemos citar Simone Lahourgue Nunes, in "Os Fundamentos e os Limites do Poder Regulamentar no Âmbito do Mercado Financeiro", Ed. Renovar, 2000, pp. 83 a 142.

37 Os principais fundamentos do poder regulamentar, a respeito dos quais mais diverge a doutrina, são justamente o poder discricionário e a atribuição constitucional ou legal de competência (cf. Diógenes Gasparini, in "Poder regulamentar", tese de mestrado mimeografada, apresentada à PUC de São Paulo, pp. 14 a 23). A diferença entre estes dois conceitos só é concebível, no entanto, para os que adotam um conceito de discricionariedade bastante restrito, necessariamente ligado apenas à intencional outorga pela lei de liberdade de escolha entre várias opçōes legítimas. Adotamos, ao revés, o conceito amplo de discricionariedade, defendido por, entre outros, Claudio Luzzati (in " $L a$ Vaghezza delle Norme", Giuffrè Editore, 1990, pp. 347/8). Com grande eloqüência, Joan Prats i Catalá também denota que "a metáfora do direito como regras do jogo é válida, mas sob a condição de aceitar que as normas fazem parte do próprio jogo, já que os atores, ainda que orientados $e$ limitados pelas normas, mantêm espaços de liberdade de ação cuja interação pode resultar a evolução e mudança das próprias normas. Se o Direito pode ser analisado como marco institucional e como instrumento, como constrição e como recurso, é precisamente porque a sua utilização está sempre sujeita a uma apreciação subjetiva" (in "Derecho y Management en las Administraciones Publicas - Notas sobre la crisis y Renovación de los respectivos paradigmas", p. 03, fonte: www.crad.org.ve, grifos nossos).

38 Apesar de não terem empregado a metodologia ora proposta, e, por vezes, sequer tratado propriamente do poder regulamentar, nos foram de grande valia as considerações de Gérard Timsit acerca dos diversos âmbitos de liberdade da atuação judicial (in "Gouverner ou Juger - Blasons de la Legalitê", Ed. Press Universitaires de France - PUF, 1995, p. 61) e a análise feita por Federico Cammeo no seu "Corso di Diritto Amministrativo", CEDAM, 1960, pp. 109 a 112. 
lei, pretensamente excludente de qualquer subjetividade por parte do seu concretizador, é uma idealização irrealizável na prática. Basta vermos a grande quantidade de divergências doutrinárias e judiciais existentes em matéria tributária e criminal, com posições jurídicas diversas, todas plausíveis.

Concordamos, todavia, com esta doutrina, se ela for concebida no sentido de que a lei deve ser formulada nos termos mais completos possíveis, não podendo, ao menos deliberadamente, deixar espaço para juízos discricionários.

Nota-se que, mesmo entre os que adotam esta doutrina em sua versão mais tradicional, há os que, sem, contudo, abandonar o feitiche da "lei soberana" (cf. nota 34), admitem a existência de regulamentos no âmbito da reserva absoluta de lei, mas desde que contenham apenas normas executivas ("sarebbe inoltre sempre necessario che contenesse soltanto norme esecutive" ${ }^{39}$ ), conceito este, todavia, bastante obscuro.

De nossa parte, entendemos que, em qualquer hipótese, mesmo na de reserva absoluta de lei, os regulamentos interpretativos são plenamente admissíveis. As leis, por mais que tentem buscar a completude absoluta, não têm como fazê-lo a ponto de não deixar qualquer margem de apreciação ao órgão concretizador do direito. $^{40}$

Como afirma HANS KELSEN, tão mal ou pouco lido quanto mal compreendido, ${ }^{41}$ " na medida em que uma norma é estabelecida através do ato, ela é um ato

39 Lorenza Calassare, in ob. cit., p. 220.

40 Quanto ao caráter, ao mesmo tempo livre e vinculado de qualquer atuação jurídica inferior ao Poder Constituinte Originário, Claudio Luzzati (in "La Vaghezza delle Norme", Giuffrè Editore, 1990, pp. 347/8), vê a existência de certo grau de liberdade, desde a atuação do juiz diante de normas pretensamente exaustivas ("Il giudice assai raramente perviene a una soluzione esatta $o$ univoca: nella maggioranza dei casi, invece, il giudice fedele al senso della legge può solo esercitare una scelta latamente politica tra una "rosa" di soluzioni compatibili con tale senso."), até o exercício do poder legislativo ("Neppure la libertà d'azione del legislatore è cosi assoluta como pare, dato che il Parlamento non può uscire dai limiti segnati dalla Costituzione"). Podemos resumir a posição do autor com a transcrição do seguinte excerto: "Ciò che varia è soltanto l'ampiezza della sfera lasciata alla discrezionalità: questa si riduce progressivamente man mano che si discende verso atti di livello più basso" (grifos nossos). Certamente existem leis que, em tese, não possibilitam um número muito grande de interpretações, número este que, no entanto, pode ser bastante aumentado em virtude da complexidade e dos conflitos de valores existentes nos casos concretos com os quais o intérprete se depara.

41 O Ministro Sepúlveda Pertence, em palestra proferida na Procuradoria Geral do Estado do Rio de Janeiro, sob o título "Atualidade do Pensamento de Kelsen", afirmou: "Digo mais, que esta prática forense, após alguns anos de estudo de Kelsen alicerçou em mim a convicção de que nós, práticos do direito, somos todos mais ou menos kelsenianos. O que há é que poucos confessam, tal a carga - tal a massa de preconceitos - que vem alimentando uma crítica implacável, que atravessa as décadas, ao grande teórico; e devo dizer, muitas delas de quem não o leu, outras tantas de quem leu, e não entendeu, e muitas outras de quem leu, entendeu, mas não quis entender... A razão da maior das críticas radicais a HANS KELSEN está em exigir da Teoria Pura do Direito que seja o que, declaradamente, não pretende ser; ou que dê aquilo que jamais se propôs a dar ao estudioso: seja uma valoração - uma apreciação livremente axiológica do conteúdo de uma ordem jurídica determinada (...)" — transcriçāo constante da RDPGE-RJ, 50/31-46. 
criador de Direito, mesmo se a função do órgão criador do Direito for determinada em alto grau pela norma superior. (...) A questão de saber se um ato é criação ou aplicação do Direito é, na verdade, de todo independente da questão de saber em que grau o órgão atuante é obrigado pela ordem jurídica. Apenas os atos pelos quais não se estabelece norma alguma podem ser mera aplicação do Direito". ${ }^{42}$

Sendo assim, os regulamentos interpretativos em matéria de reserva absoluta de lei, desde que a esta seja a mais exaustiva possível, não agridem os valores do Estado De Direito, mas, ao contrário, potencializa-os ao uniformizar a interpretação a ser dada à lei pelos diversos agentes da Administração Pública, dando, desta forma, maior eficácia aos princípios da igualdade e da transparência administrativa. ${ }^{43}$

Nesta senda, Bernard Schwartz ${ }^{44}$ afirma que nada impede que, além do poder regulamentar comum, seja sempre possível à Administração, independentemente de qualquer autorização específica, expedir regulamentos interpretativos das normas que tem que aplicar. Noticia ainda o autor que a Suprema Corte Norte-Americana não apenas admite os regulamentos interpretativos, como, salvo se implausíveis, lhes dá preferência frente às demais interpretações possíveis.

b) Leis de grande densidade normativa: Pela doutrina mais tradicional, toda lei já deveria, de per se, normatizar suficientemente a matéria, a fim de que os regulamentos apenas detalhassem as obrigações por ela previamente estabelecidas. Sendo assim, para essa corrente doutrinária, apenas poderiam ser emitidos os ditos "regulamentos meramente executivos". ${ }^{45}$

Verifica-se, no entanto, uma contradição nos próprios termos utilizados por estes autores: se, para eles, a lei, por si própria, já estabelece a obrigação, o que deveria significar a pré-determinação dos seus sujeitos e objeto - de todos os elementos da prestação devida -, não haveria espaço para regulamento algum - que não consistisse na mera repetição da lei. Os, por eles chamados, "regulamentos de execução" seriam, destarte, necessariamente inócuos.

42 In "Teoria Geral do Direito e do Estado", Ed. Martins Fontes, 1998, trad. Luís Carlos Borges, p. 195. Observa-se que, ao se referir a "normas", o autor está tratando tanto das abstratas, como das concretas, emitidas, via de regra, pelo administrador ou pelo juiz. Para ele não teriam qualquer conteúdo criativo de direito apenas os atos de execução material de decisões jurídicas anteriormente tomadas (ex.: demoliçōes, prisões, apreensões, etc.).

43 A distinção feita entre regulamentos interpretativos e criadores de direito deve ser tomada em termos, vez que, afinal, toda interpretação é, já vimos, em maior ou em menor escala, tanto criação como aplicação do Direito (cf., entre outros, Hans Kelsen, in ob. e p. cit., Mauro Cappelletti, in "Juizes Legisladores?", Sérgio Antonio Fabris Editor, 1999, trad. Carlos Alberto Álvaro de Oliveira, e Maurice Hauriou, in ob. cit., pp. 183/4).

44 In "American Administrative Law", Sir Isaac Pitman \& Sons Ltda., London, 1950, pp. 34/5.

45 Na doutrina brasileira, Luciano Ferreira Leite defende com brilhantismo tal posição (in " $O$ Regulamento no Direito Brasileiro", Ed. RT, 1986). O mesmo é feito por Diógenes Gasparini, que ressalva apenas alguns regulamentos, por ele chamados de autônomos, admitidos excepcionalmente pela Constituição (cf. ob. cit.). 
O que, no entanto, segundo esta doutrina, haveria em tais casos, seria a concessão de discricionariedade à autoridade administrativa regulamentadora para detalhar 0 conteúdo da obrigação já estabelecida em lei. Ora, se há detalhamento da obrigação, há criação, mesmo que moderada - não mera execução - de alguns aspectos dos elementos da prestação; se foi concedida discricionariedade, há juízo de conveniência e oportunidade administrativa na determinação do exato conteúdo da obrigação imposta.

Sendo assim, apenas a adoção do termo "execução" em sentido lato, compreensivo, como sabemos (cf. nota 40), também dos atos criadores de direito, poderia servir para denominar adequadamente esses regulamentos.

c) Leis de baixa densidade normativa: Nas situações descritas no subitem "b" supra, a lei chega a iniciar - sem pretender esgotar - a normatização da matéria de maneira bem detalhada. Na hipótese ora tratada, ao revés, a lei estabelece apenas parâmetros bem gerais da regulamentação a ser efetuada pela Administração Pública. Trata-se das leis-quadro (lois-cadre) ou standartizadas, próprias das matérias de grande complexidade técnica ou suscetíveis de constantes mudanças.

Detalhando a necessidade destas leis, Giuseppe Abbamonte ${ }^{46}$ adverte que diante de uma realidade de grande complexidade, decorrente da crescente concentração dos centros de poder econômico, se requer ações capazes de identificar e individuar obrigações, acompanhar o seu cumprimento, fixando, inclusive, regras de comportamento, inserindo-se na realidade, guiando-a e, possivelmente, corrigindo-a, ou, ao menos, reequilibrando as tendências desestabilizadoras.

Estas leis, em processo de franca proliferação, não dão maiores elementos pelos quais o administrador deva pautar a sua atuação ou regulamentação, referindo-se, genericamente, a valores morais, políticos e econômicos existentes na sociedade (saúde pública, utilidade pública, competição no mercado, universalização do ensino, preços abusivos, continuidade dos serviços públicos, regionalização etc.).

O administrador terá grande poder de integração do conteúdo da vontade do legislador, já que o objetivo das leis assim formuladas é exatamente "introduzir uma vagueza que permita o trato de fenômenos sociais, muito fugazes para se prestarem ao aprisionamento em uma regra precisa". ${ }^{47}$

Destaque-se que, ao empregarmos a expressão "quadros estabelecidos pela lei", não estamos tratando apenas de determinado diploma legislativo, mas do conjunto do ordenamento jurídico (a própria Constituição, leis e demais atos com força de

46 In "Gli Enti Pubblici - L'Amministrazione per Settori organici", que constitui o Volume Oitavo do "Trattato di Diritto Amministrativo", dirigido por Giuseppe Santaniello, CEDAM, Padova, 1990, p. 87.

47 Danièle Bourcier, in "La Décision Artificielle", Ed. Press Universitaires de France - PUF, 1995, p. 61. Maurice Hauriou destaca a grande importância desta técnica legislativa no direito administrativo, vez que "o standard, flexivel e mutável, representa no direito o elemento de mobilidade” (in ob. cit., pp. 150/1, grifamos). 
lei), que, explícita ou implicitamente, em seu sistema, confira poder regulamentar sobre determinada matéria, não nos sendo dado ficar presos à letra da lei para definirmos a sua existência ou não. ${ }^{48}$

É de se destacar, para este efeito, o grande âmbito do poder regulamentar implicitamente atribuído pelo conjunto do ordenamento jurídico, âmbito no qual, muitas vezes, a Administração tem poder regulamentar implicitamente conferido pela própria Constituição (porquê haveria poder para regulamentar leis ordinárias e não a própria lei constitucional?), poder regulamentar este que pode vir a ser extraído até mesmo das normas constitucionais programáticas. ${ }^{49} \mathrm{Se}$, por exemplo, a Constituição estabelece que a Administração Pública deve prestar determinado serviço público (fim), não teria sentido que ela, independentemente da existência de lei ordinária, não pudesse regulamentar a sua prestação (meio). ${ }^{50}$ Nestas circunstâncias, aquelas competências só alcançarão os seus propósitos se estas (regulamentares) forem admitidas.

Com isto, não estamos "forçando" o conteúdo da Constituição, mas apenas aplicando o vetusto princípio dos "implied powers", por Marshall concebido nos seguintes termos: "legítimo o fim e, dentro da esfera da Constituição, todos os meios que sejam convenientes, que plenamente se adaptem a este fim e que não estejam proibidos, mas que sejam compatíveis com a letra e o espírito da Constituição, são constitucionais." 51

Neste sentido, o Supremo Tribunal Federal, em recente acórdão relatado pelo Ministro Carlos Velloso, inferiu da competência conferida pelo art. 237 da Constituição Federal ao Ministério da Fazenda para "a fiscalização e o controle sobre o comércio exterior, essenciais à defesa dos interesses fazendários nacionais", a possibilidade deste, independentemente da "existência de lei formal", vedar a importação de pneumáticos usados. ${ }^{52}$

48 A respeito da pobreza da interpretação meramente literal, vale citar a espirituosa passagem do voto proferido pelo Min. Luiz Galloti trazido à lume por Luís Roberto Barroso: "De todas, a interpretação literal é a pior. Foi por ela que Cléia, na Chartreuse de Parme, de Stendhal, havendo feito um voto a Nossa Senhora de que não mais veria seu amante Fabrício, passou a recebê-lo na mais absoluta escuridão, supondo que assim estaria cumprindo o compromisso" (apud Luís Roberto Barroso, in "Interpretação e Aplicação da Constituição", Ed. Saraiva, 1996, p. 120).

49 Roberto Bin, in "Atti Normativi e Norme Programatiche", Giuffrè Editore, 1988, passim. so Cf. Eros Roberto Grau, in " $O$ Direito Posto $e$ o Direito Pressuposto", Ed. Malheiros, 2" ed., 1998, p. 188. Somos levados a esta conclusão até mesmo em razão da utilização pela nossa Lei maior (art. $\left.5^{\circ}, \mathrm{II}\right)$ da locução "em virtude de lei", sendo ilógico considerar que ela própria teria se excluído.

51 Apud Rodolfo Bledel, in "Introducción al Estudio del Derecho Publico Anglosajón", Editorial Depalma, Buenos Aires, 1947, p. 57.

52 In Cadernos de Direito Constitucional e Ciência Política, Ed. RT, 26/291-4. Temos, no entanto, algumas reservas a esta decisão, tendo em vista que as razōes da vedação da importação de pneus usados são de índole primordialmente ambiental, ao passo que a competência prevista no art. 237 foi, claramente, conferida para finalidades fazendárias. 
Não basta, todavia, que o poder normativo possua fundamento, explícito ou implícito, no ordenamento jurídico. Mister se faz também que este forneça parâmetros suficientes para que a legalidade e/ou a constitucionalidade do regulamento a ser expedido possa ser aferida. Do contrário, estaríamos impossibilitando qualquer forma de controle sobre tais atos, o que não se coadunaria com o Estado de Direito.

Tais balizamentos podem ser extraídos tanto da letra de alguma disposição do ordenamento jurídico, como do seu espírito como um todo. Neste sentido, a Suprema Corte Norte-Americana já decidiu que o simples parâmetro que impõe ao regulamento a realização do "interesse público" pode, dependendo do caso, ser legítimo: "O termo "interesse público", tal como empregado, não é um conceito desvestido de critérios, mas possui relação direta com a adequação dos serviços de transporte, com as suas condições essenciais de economia e eficiência (...)".53

Do que já expomos no presente Tópico, infere-se que os poderes regulamentares tratados neste subitem e nos dois anteriores são essencialmente os mesmos, havendo apenas uma variação nos seus respectivos graus de amplitude, para os quais deve o intérprete estar atento, já que nem sempre são facilmente distinguíveis.

Assim, se adotarmos um conceito de "execução" amplo, consistente no desenvolvimento de normas pré-estabelecidas, todos os regulamentos acima analisados serão "de execução", ${ }^{54}$ o que deverá satisfazer aqueles apegados à interpretação meramente literal do art. 84, IV, in fine, da Constituição Federal ("decretos e regulamentos para a fiel execução da lei").

Por outro lado, se tivermos em mente que, salvo em raríssimas hipóteses, as atividades do administrador público, ou mesmo do juiz, também são criadoras de Direito, já que não há como se limitarem à mera execução da lei, ${ }^{55}$ todos os regulamentos serão, em certa e em variável medida, "autônomos" ou "independentes", a depender da nomenclatura adotada.

53 Apud Bernard Schwartz, in ob. cit., p. 26.

54 "Mesmo os regulamentos independentes não têm fundamento distinto daquele dos outros regulamentos, (...) vez que servem, como os outros regulamentos, à execução de uma lei: particularmente daquelas leis que atribuem à Administração um determinado poder, mesmo que sem discipliná-lo sequer em suas linhas gerais. Nos regulamentos de execução, a maior parte das normas concernentes a uma determinada matéria já se encontra disciplinada na lei, de maneira que o regulamento não tem outra finalidade além de acrescentar novas disposições, e a matéria permanece regulada principalmente pela lei e subsidiariamente pelo regulamento: nos regulamentos independentes, ao revés, a parte principal da disciplina da matéria é assumida pelo regulamento dada a exiguiidade da norma legislativa" (Carlo Saltelli, in "Potere Esecutivo e Norme Giuridiche", Mantellate, Roma, 1926, pp. 103/4).

55 "Todo jurista sabe a larga margem de arbítrio que as formulações do direito positivo deixam ao intérprete, e como todo sistema jurídico, embora aparentemente "fechado", tem na realidade as suas válvulas, os seus meios naturais de renovação, transformaçāo e desenvolvimento" (Giorgio Del Vecchio, in ob. cit., p. 588). A respeito ver também as notas 37 e 40 supra. 


\section{III.1 - Delegificação}

O instituto da delegificação constitui fenômeno inteiramente distinto das manifestações de poder regulamentar acima analisadas, nas quais o legislador, no uso da sua liberdade para dispor sobre determinada matéria, atribui um maior ou menor campo de atuação normativa à Administração, que permanece, em todo caso, subordinada às leis formais preexistentes e aos balizamentos por elas formulados. Os regulamentos assim expedidos não podem revogar leis anteriores e são revogáveis por leis posteriores. Por isto, entendemos que não podem ser impugnados mediante o argumento de ter havido delegação de poder legislativo - integram o Direito positivo, mas não possuem força de lei.

De maneira diversa, a delegificação consiste, nas palavras de Diogo de Figueiredo Moreira Neto, ${ }^{56}$ primeiro a, entre nós, tratar da matéria, na "retirada, pelo próprio legislador, de certas matérias, do domínio da lei (domaine de la loi) passando-as ao domínio do regulamento (domaine de l'ordonnance)."

O Mestre Eduardo García de Enterría ${ }^{57}$ conceitua a delegificação ou deslegalização como "a operação efetuada por uma lei que, sem entrar na regulação material do tema, até então regulado por uma lei anterior, abre tal tema à disponibilidade do poder regulamentar da Administração. Mediante o princípio do contrarius actus, quando uma matéria está regulada por determinada lei se produz o que chamamos de "congelamento do grau hierárquico" normativo que regula a matéria, de modo que apenas por outra lei contrária poderá ser inovada dita regulação. Uma lei de deslegalização opera como contrarius actus da anterior lei de regulação material, porém, não para inovar diretamente esta regulação, mas para degradar formalmente o grau hierárquico da mesma de modo que, a partir de então, possa vir a ser regulada por simples regulamentos. Deste modo, simples regulamentos poderão inovar e, portanto, revogar leis formais anteriores, operação que, obviamente, não seria possível se não existisse previamente a lei degradadora."

Mais adiante, destaca que a lei de deslegalização "não é uma lei de regulação material, não é uma norma diretamente aplicável como norma agendi, não é uma lei cujo conteúdo deva simplesmente ser completado; é uma lei que limita seus efeitos a abrir aos regulamentos a possibilidade de entrar em uma matéria até então regulada por lei", ${ }^{58}$ ressalvadas as matérias resguardadas por reserva absoluta de lei formal, como são, entre nós, os tributos e os crimes. ${ }^{59}$

Por este entendimento, não haveria qualquer inconstitucionalidade na delegificação, que não consistiria propriamente em uma transferência de poderes legislativos, mas apenas na adoção, pelo próprio legislador, de uma política legislativa pela qual

56 In "Mutações do Direito Administrativo", Ed. Renovar, 2000, p. 166.

57 In "Legislación Delegada, Potestad Reglamentaria y Control Judicial", Civitas, Madrid, 3" ed., 1998, pp. 220/1.

58 Ibid.

59 Autor e ob. cit., pp. 223/4. 
transfere a uma outra sede normativa a regulação de determinada matéria. E, com efeito, se este tem poder para revogar uma lei anterior, por que não o teria para, simplesmente, rebaixar o seu grau hierárquico? Por que teria que direta e imediatamente revogá-la, deixando um vazio normativo até que fosse expedido o regulamento, ao invés de, ao degradar a sua hierarquia, deixar a revogação para um momento posterior, a critério da Administração Pública, que tem maiores condições de acompanhar a avaliar a cambiante e complexa realidade econômica e social?

Há, contudo, opiniões que sustentam que tal deslocamento de sede normativa só pode ser operada pela própria Constituição, isto é, que a liberdade do legislador, num regime de Constituição rígida, não pode chegar ao ponto de abrir mão dos seus poderes, delegando-os. Para a correção desta assertiva, pouco importaria se a Constituição veda ou não expressamente a delegação de poderes. Esta vedação já decorreria da própria divisão constitucional de competências. Sendo assim, para esta corrente doutrinária, a admissão da delegificação por via legislativa implicaria na derrogação infraconstitucional de competências fixadas pelo Poder Constituinte. ${ }^{60}$

Vezio Crisafulli, ${ }^{61}$ cuja inestimável contribuição à teoria da aplicabilidade das normas constitucionais tantas marcas deixou no Direito brasileiro, expressa a sua opinião neste sentido ao afirmar que "o fenômeno consistiria, então, na desqualificação, disposta expressamente pela lei, de determinada norma, originariamente legislativa, a qual viria a ser atribuída estatura regulamentar: de maneira que, não seria o regulamento sucessivo que adquiriria (inadmissivelmente) força de lei, mas as normas delegificadas que viriam a ter força passiva de fontes regulamentares. A reconstrução gera, todavia, perplexidade, porque, desqualificando algumas de suas próprias disposições ou de outra lei, a lei estaria em substância, demitindo-se da força que por natureza lhe é própria, contrastando com as normas constitucionais que a disciplinam enquanto lei."

Refutando este argumento, Eduardo García de Enterría observa que "um setor da doutrina italiana, tratando sempre do conceito de delegação como transferência de poder, tem, sob este pressuposto, visto a delegação como transferência do poder ab-rogatório da lei. Porém, o argumento, que é sutil, não, é todavia, correto. A ab-rogação da lei anterior por norma deslegalizada não é um poder próprio, mas uma simples conseqüência da degradação normativa legalmente operada. Por outro

60 Apesar de não assumir expressamente uma posição neste sentido, Giuseppe de Vergottini (in "A Delegificação e a sua Incidência no Sistema de Fontes do Direito", trad. Fernando Aurélio Zilveti, constante da citada obra coletiva "Direito Constitucional - Estudos em Homenagem a Manoel Gonçalves Ferreira Filho"), expõe de forma minuciosa o entendimento dos autores italianos que sustentam a inconstitucionalidade das delegificações infra-constitucionais, e, ao final do seu texto, conclui: "A importância de tal deslocamento, se por um lado é indício da revigoração do poder do Executivo, por outro lado impõe que mudanças assim radicais da forma de governo não possam ser confiadas à intervenção contingente do legislador, mas se traduzem numa revisão das normas constitucionais relativas à distribuição dos poderes normativos entre Parlamento e Governo" (p. 176).

61 In "Lezione di Diritto Costituzionale", II, 1, CEDAM, 1993, pp. 154/5. 
lado, a Administração se utiliza da delegação ínsita na deslegalização não apenas no momento do primeiro exercício da mesma, como também posteriormente, quando substitui esta primeira norma por outras igualmente regulamentares, momento no qual é evidente que não está ab-rogando ou inovando leis, mas suas próprias disposições regulamentares anteriores. A técnica da deslegalização se limita a esse plano formal de manipulação sobre o grau hierárquico (manipulação que também se conhece em sentido contrário, com uma elevação da hierarquia normativa de uma regulação regulamentar)," ${ }^{62}$ devendo ser ressaltado também que o legislador pode, naturalmente, retomando a normatização da matéria, revogar a lei delegificadora.

Ressaltamos que, mesmo para os que não acolhem a delegificação por via legislativa, o instituto tem grande importância no Direito positivo brasileiro, já que, em diversos casos, é a própria Constituição que opera a delegificação em favor de entidades estatais e até não estatais: em favor das entidades desportivas privadas (art. 217, I), ${ }^{63}$ dos órgãos reguladores da prestação dos serviços de telecomunicações (art. 21, XI) e da exploração do petróleo (art. 177, § $\left.2^{\circ}, \mathrm{III}\right),{ }^{64}$ das universidades em geral (art. 207) ${ }^{65}$ etc. $^{66}$

Em todas essas hipóteses, por sua sede constitucional, temos uma reserva inquestionavelmente legítima de poder normativo delegificado em favor de órgãos ou entidades estranhas ao Poder Legislativo. E mais, como essas esferas normativas autônomas fundamentam-se diretamente no Poder Constituinte, estão protegidas contra as ingerências que a elas venham a ser impostas, ressalvada, naturalmente, a incidência de normas da própria Constituição e a possibilidade de ponderação legislativa entre as várias normas e valores constitucionais pertinentes. ${ }^{67}$

62 Ob. cit., p. 221.

63 Cf. Álvaro Melo Filho, in "Desporto na Nova Constituição", Ed. Sergio Fabris, 1990, passim.

64 Cf. Diogo de Figueiredo Moreira Neto, in ob. cit., pp. 170/1.

65 Cf. Nina Ranieri, in "Autonomia Universitária", EDUSP, 1994, passim.

66 Para um desenvolvimento do tema versado no presente artigo sob o ponto de vista específico das agências reguladoras independentes, aplicando-se a elas a Teoria dos Ordenamentos Setoriais de Massimo Severo Giannini (ob. cit., 171/5), ver o nosso "Os Ordenamentos Setoriais e as Agências Reguladoras Independentes", constante da obra coletiva "Direito Político", organizada por Diogo de Figueiredo Moreira Neto, Ed. Lumen Júris/APERJ, Rio de Janeiro, 2000.

67 Tratando do Direito português, mas em lição analogamente aplicável ao nosso Direito Público, Jorge Reis Novais assim expõe a proteção jurídica das autonomias constitucionalmente asseguradas: "Trata-se, em todos estes casos, nomeadamente no que respeita às autarquias locais, universidades e associações públicas, de autonomia, em grande medida, sob reserva de lei, pelo que a Assembleia da República tem aí uma ampla margem de decisão legislativa. Porém, na medida em que aquela autonomia tem igualmente um apoio constitucional, a margem de decisão da Assembleia da República não é ilimitada. (...) O legislador não pode, também aqui, afectar o núcleo essencial desta autonomia, sob pena de violação das garantias institucionais que estes valores constituem", o que revela o "significado da autonomia e da descentralização como limites ao poder da maioria democrática" (in "Separação de Poderes e Limites da Competência Legislativa da Assembleia da República”, Ed. LEX, Lisboa, 1997, pp. 71/2). 


\section{IV - Conclusão}

Grande parte dos nossos esforços visaram à necessária desmistificação da lei formal, sem o que não poderíamos ter a dimensão exata do amplo e multifacetário poder normativo atribuído à Administração Pública no Estado contemporâneo.

Entendemos que, apesar de certos aspectos da matéria, principalmente a delegificação, ainda causarem alguma perplexidade aos setores da doutrina e da jurisprudência contumazmente infensos a mudanças de posições tradicionais, a necessidade prática de uma regulação social ágil e eficiente irá, sem maior demora e desde que observados os canônes do Estado de Direito, levar à majoritária aceitação dos largos termos em que hoje, de fato, já se encontra o poder normativo da Administração Pública. ${ }^{68}$

O Poder Legislativo e a própria Constituição, face à complexidade, dinamismo e tecnicização da sociedade, têm destacado os aspectos políticos da normatização social, retendo-os em sua esfera competencial, mas, consciente das suas naturais limitações, têm transpassando a outros órgãos ou entidades grande parte da competência normativa estatal, resguardando sempre, porém, como não poderia deixar de ser, o seu balizamento e coordenação.

68 Como exemplo de novos institutos jurídicos que, em um primeiro momento geram perplexidades, mas que, posteriormente, passam a ser aceitos sem maiores discussões, podemos citar o caso da federação, que, no momento em que surgiu, era considerada pela maioria da doutrina como um verdadeiro atentado à indivisibilidade da soberania, mas que, hoje, é matéria tranqüila (cf. João Barbalho, in Edição fac-similar dos "Comentários à Constituição Federal de 1891", Secretaria de Documentação e Informação do Senado Federal, 1992, p. 10). 


\section{A Fraude à Lei}

Regis Fichtner Pereira

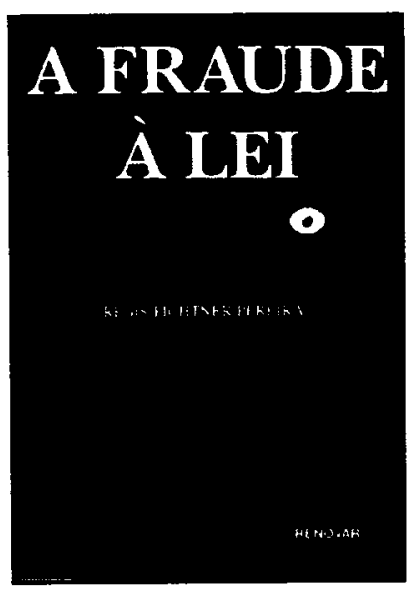

O tema tratado neste livro é de grande relevancia e atualidade. Trata-se de figura jurídica componente da chamada Teoria Geral do Direito, de aplicação a todos os ramos da ciência jurídica. A fraude à lei é tratada de forma sistemática, sem que o autor tenha se prendido a determinado ramo do Direito. O estudo foi elaborado com amplitude e dentro de parâmetros científicos, suficientes a auxiliar o intérprete e aplicador da lei na soluçāo de questōes jurídicas em que ocorra a violação indireta da norma jurídica.

Ref. 0065

Form. 14x21

Brochura

1994

142 págs.

\section{A Idéia de Liberdade no Estado Patrimonial e no Estado Fiscal}

Esta obra trata da necessidade do momento atual de detectar os ranços e os condicionamentos negativos do patrimonialismo e do cartorialismo, que impregnaram a nossa mentalidade e que até agora dificultaram ao Brasil o ingresso pleno na modernidade, tudo sem prejuízo de observar que apreendemos, pela investigação da filosofia prática, em sua essência, a idéia de liberdade, transubstanciada na fiscalidade centralizada e na publicização dos impostos.

Ref. 0033 Brochura 196 págs.

Ricardo Lobo Torres

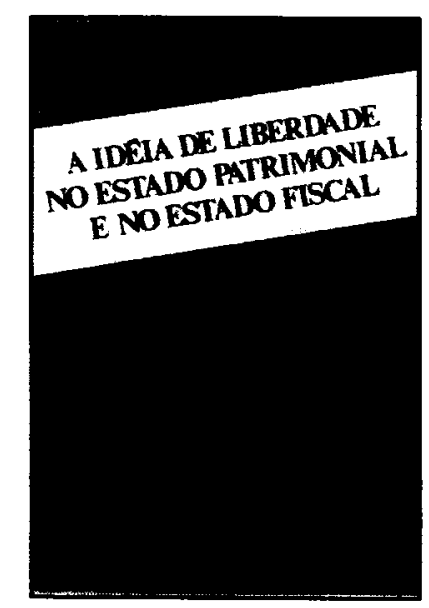

